\section{Urbanisation and incidence of psychosis}

\section{and depression}

Follow-up study of 4.4 million women and men in Sweden ${ }^{\dagger}$

KRISTINA SUNDQUIST, GÖLIN FRANK and JAN SUNDQUIST

\author{
Background Previous studies of \\ differences in mental health between \\ urban and rural populations are \\ inconsistent.
}

Aims To examine whether a high level of urbanisation is associated with increased incidence rates of psychosis and depression, after adjustment for age, marital status, education and immigrant status.

Method Follow-up study of the total Swedish population aged 25-64 years with respect to first hospital admission for psychosis or depression. Level of urbanisation was defined by population density and divided into quintiles.

Results With increasing levels of urbanisation the incidence rates of psychosis and depression rose. In the full models, those living in the most densely populated areas (quintile 5) had 68-77\% more risk of developing psychosis and 12 $20 \%$ more risk of developing depression than the reference group (quintile I).

\section{Conclusions A high level of}

urbanisation is associated with increased risk of psychosis and depression for both women and men.

Declaration of interest None. Funding detailed in Acknowledgements.

†See editorial, pp. 287-288, this issue.
Although urbanisation in Western countries has led to profound psychosocial changes in people's lives, previous research on the effect of urbanisation on mental health has been inconsistent. For example, a few studies in the Netherlands showed that urbanisation was associated with psychotic disorders (Marcelis et al, 1998; van Os et al, 2001, 2002), and some studies from the USA revealed higher urban than rural rates of depression (Blazer et al, 1987; Neff \& Husaini, 1987). Other studies from the USA and the UK found no urban-rural difference in mental health (Romans-Clarkson et al, 1990; Robins \& Regier, 1991; Kessler et al, 1994; Parikh et al, 1996). We wished to shed new light on this inconsistency. For this purpose we analysed the whole Swedish adult population aged 25-64 years in a longitudinal study of incidence rates of both psychosis and depression. The aim of this study was to examine whether a high level of urbanisation is associated with an increased risk of developing psychosis and depression for both women and men, after adjustment for individual demographic and socioeconomic characteristics.

\section{METHOD}

\section{Study population and information sources}

Our follow-up study investigated the entire Swedish population, in total 4.4 million women and men aged 25-64 years on 31 December 1996. The individuals were followed from 1 January 1997 to 31 December 1999, until first admission to hospital for treatment of psychosis or depression, death from any cause, emigration from Sweden, or until the end of the study. A total of 35727 individuals with previous hospital admissions for psychosis or depression during 1992-1996 were excluded. Information on demographic and socioeconomic characteristics was obtained from a national database holding annual individual data for the whole Swedish adult population. Personal identification numbers were used to link these data to the Swedish Hospital Discharge Register at the National Board of Health and Welfare. All individuals had been previously geocoded to their area of residence or small-area market statistics (SAMS) level, which allowed us to include the level of urbanisation in the study. The whole of Sweden is divided into 9667 SAMS areas. The average population in each SAMS area is approximately 2000 persons for Stockholm and 1000 persons for the rest of Sweden. A total of 135719 individuals $(3 \%)$ were excluded from the study because of missing SAMS codes and/or other explanatory variables, or because they lived in SAMS areas with fewer than 50 individuals; such areas were excluded from the study because of unstable statistical estimates. The analysis eventually included 8135 SAMS areas.

\section{Outcome variable}

Psychiatric morbidity was defined as the first admission to hospital for treatment of psychosis or depression defined according to ICD-9 and ICD-10 (World Health Organization, 1978, 1992). There were two diagnostic groups: psychosis (ICD-9 codes 295, 297, 298C, 298E, 298W, 298X; and ICD-10 codes F20-25, F28, F29) and depression (ICD-9 codes 296, 298A, 298B, 300E, 301B, 311; ICD-10 codes F30-34, F38, F39). The DSM-IV (American Psychiatric Association, 1994) was also used as an instrument in the process of diagnosis.

\section{Explanatory variables}

The study population was categorised by gender, and by age into the following groups: $25-34$ years, 35-44 years, 45-54 years, and 55-64 years of age at the start of study. Level of urbanisation was classified into quintiles by dividing all 4.4 million individuals into five groups according to the population density in the SAMS area where they lived. The population density was calculated as the number of people living in the SAMS area divided by the area in $\mathrm{km}^{2}$. The quintiles were classified as follows: quintile $1, \leqslant 19$; quintile 2,20 273 ; quintile $3,274-818$; quintile 4,819 2278 ; quintile $5, \geqslant 2279$ (all values in persons per $\mathrm{km}^{2}$ ). 
Marital status was classified in two categories: living alone, and married/ cohabiting. Only individuals with children in common registered at the same property were counted as being cohabiting. Cohabiting without children in common is registered in the national database as 'single', and therefore in this study was counted as 'living alone'.

Attained level of education was used as a measure of socio-economic status and classified into three categories: 'low' (compulsory school), 'middle' (at most 2 years of university study) and 'high' (at least 3 years of university study).

Immigrant status was classified into three groups. The first group consisted of people born in countries with mainly labour-related immigration to Sweden (southern European countries and member states of the Organisation for Economic Co-operation and Development); the second group consisted of people born in countries often referred to as refugee countries (Eastern European countries, Bosnia, and all other non-European countries); and the third group consisted of Swedishborn people.

We performed separate analyses for women and men because of the gender differences in psychiatric disease established in previous research. Moreover, many psychiatric disorders decline with increasing age and socio-economic status, which is why we included age and attained level of education in the analysis (Kessler et al, 1994). Marital status was included in the analysis because of its relationship with, for example, depression (Carroll et al, 2003). Finally, the importance of immigrant status for mental health was recently confirmed by the Swedish National Institute of Public Health (Sundquist \& Johansson, 2002) and by a longitudinal study of different migrant groups in Sweden (Westman et al, 2003).

During the follow-up $30 \%$ of the population had moved from one SAMS area to another. Therefore, we added the variable moved/not moved in an additional analysis (data not shown).

\section{Statistical analysis}

The SAS software package (version 6) was used in the statistical analyses (SAS, 1989). Age-standardised incidence rates (per 100000 persons per year) of psychosis and depression were calculated by indirect age standardisation, with Sweden as the standard population (Breslow \& Day, 1987). A Cox regression model
(Kleinbaum, 1995) was used to estimate the hazard ratios of psychosis and depression in the different background variables. The results are shown as hazard ratios (HR) with $95 \%$ confidence intervals. Risk time was calculated from the start of study until the first admission to hospital because of psychosis or depression, death from all causes, emigration from Sweden, or end of the study. The proportional hazards assumption was tested for parallelism by studying $\log (-\log ()$.$) of survival curves.$ All variables met the assumption; no interaction between the explanatory variables and time was found.

The study was approved by the ethics committee at the Karolinska Institute, Stockholm.

\section{RESULTS}

During the 3 years of the study there were 3133 and 3030 incident cases of psychosis and 6357 and 4721 incident cases of depression in women and men respectively. Table 1 shows the age-adjusted incidence rates of psychosis and depression for the five levels of urbanisation and for the explanatory variables. There was a clear gradient between level of urbanisation and

Table I Population and age-adjusted incidence rates for psychosis and depression in women $(n=2$ I89 I90) and men ( $n=2248301)$ aged $25-64$ years

\begin{tabular}{|c|c|c|c|c|c|c|}
\hline \multirow[t]{2}{*}{ Variable } & \multicolumn{2}{|c|}{ Population } & \multicolumn{2}{|c|}{ Psychosis } & \multicolumn{2}{|c|}{ Depression } \\
\hline & $\begin{array}{c}\text { Women } \\
n\end{array}$ & $\begin{array}{c}\text { Men } \\
n\end{array}$ & $\begin{array}{c}\text { Women } \\
\operatorname{Rate}^{2}(95 \% \mathrm{Cl})\end{array}$ & $\begin{array}{c}\text { Men } \\
\operatorname{Rate}^{2}(95 \% \mathrm{Cl})\end{array}$ & $\begin{array}{c}\text { Women } \\
\text { Rate }^{2}(95 \% \mathrm{Cl})\end{array}$ & $\begin{array}{c}\text { Men } \\
\operatorname{Rate}^{2}(95 \% \mathrm{Cl})\end{array}$ \\
\hline \multicolumn{7}{|l|}{ Urbanisation } \\
\hline QI (lowest) & 422136 & 467192 & $30(29-32)$ & $32(31-34)$ & $84(82-86)$ & $67(65-69)$ \\
\hline Q2 & 439805 & 449532 & $34(33-36)$ & $31(30-32)$ & 87 (85-89) & $66(64-68)$ \\
\hline Q3 & 445911 & 441983 & $40(38-4 I)$ & $38(37-40)$ & $90(88-92)$ & $66(64-68)$ \\
\hline Q4 & 442904 & 443485 & $56(54-58)$ & $53(51-54)$ & $107(104-109)$ & 71 (69-73) \\
\hline Q5 (highest) & 438434 & 446109 & $84(81-86)$ & $75(73-77)$ & $122(120-125)$ & $87(85-90)$ \\
\hline \multicolumn{7}{|l|}{ Marital status } \\
\hline Living alone & 864792 & 1000772 & 90 (87-92) & $90(88-92)$ & $135(133-138)$ & $103(100-105)$ \\
\hline Married/cohabiting & I 324398 & I 247529 & $26(24-27)$ & $16(15-17)$ & $79(76-8 I)$ & $53(51-54)$ \\
\hline \multicolumn{7}{|l|}{ Education } \\
\hline Low & 508496 & 600235 & $74(72-76)$ & $74(72-76)$ & $129(126-132)$ & $88(86-90)$ \\
\hline Middle & | 408842 & I 363667 & $43(42-45)$ & 40 (39-42) & 93 (91-95) & $68(66-70)$ \\
\hline High & 271852 & 284399 & $36(35-38)$ & $24(23-25)$ & $82(80-84)$ & $58(56-59)$ \\
\hline \multicolumn{7}{|l|}{ Immigrant status } \\
\hline Labour migrant & 159217 & 148564 & 75 (73-77) & $64(62-66)$ & $126(123-128)$ & $77(75-80)$ \\
\hline Refugee & 128108 & I3I 294 & $85(83-88)$ & $80(78-82)$ & $123(120-126)$ & $82(80-84)$ \\
\hline Swedish-born & 1901864 & 1968443 & $43(42-45)$ & $42(40-43)$ & $94(91-96)$ & 69 (67-7I) \\
\hline
\end{tabular}

I. Immigrant status was not known for one woman.

2. Incidence rate per 100000 person-years. 
incidence rates of psychosis and depression for both women and men. Table 2 shows the age-adjusted and full models for women. The age-adjusted model is shown because psychiatric disorders decline with increasing age (Kessler et al, 1994). In the age-adjusted model there was a clear gradient between level of urbanisation and the risk of developing both psychosis and depression for women. For example, in quintile 5 (the highest level of urbanisation), the risks of developing psychosis and depression were 166 and $43 \%$ higher than in quintile 1 , respectively (psychosis, $\mathrm{HR}=2.66$, 95\% CI 2.36-2.99; depression, $\mathrm{HR}=1.43$, 95\% CI $1.32-1.55)$. The gradients between level of urbanisation and the risk of developing psychosis and depression remained in the full models, adjusted for marital status, attained level of education, and immigrant status. For example, in quintile 5 the hazard ratios for psychosis and depression for women were 1.77 (95\% CI 1.57-1.99) and 1.20 (95\% CI 1.11-1.30), respectively.

Table 3 shows the age-adjusted and full models for men. The results show patterns similar to those for women, with a clear gradient between level of urbanisation and risk of developing psychosis or depression.
For example, for men living in the most urbanised areas, the risks of developing psychosis or depression were $125 \%$ and $27 \%$ higher than for those in the least urbanised areas. These increased risks decreased slightly but remained significant after adjustment for marital status, attained level of education and immigrant status. In the full model, men living in the most urbanised areas (quintile 5), had $68 \%$ and $12 \%$ higher risks of developing psychosis and depression, respectively, than men in the least urbanised areas. When we added the variable 'moved/not moved', the hazard ratios remained almost unaltered: for example, in the full models the hazard ratios for psychosis in quintile 5 were 1.76 (95\% CI 1.55-198) for women and 1.67 (95\% CI 1.49-1.88) for men (data not shown).

There was also a clear association between the covariates marital status, attained level of education and immigrant status, and our outcome variables. For example, in the full model the hazard ratio for psychosis in quintile 5 for people living alone was 6.02 (95\% CI 6.45-6.64) for men and 3.23 (95\% CI 2.98-3.49) for women. A similar pattern was observed for low educational attainment. Individuals categorised as labour migrants or refugees exhibited increased risks of developing psychosis and depression.

\section{DISCUSSION}

The main finding of this follow-up study was that a high level of urbanisation was associated with increased incidence rates of psychosis and depression for both women and men. This association remained after adjustment for age, marital status, attained level of education and immigrant status, and was more pronounced for psychosis than for depression. Moreover, the covariates living alone and low educational attainment were strongly associated with psychosis and depression, especially for men.

\section{Other studies}

Our findings of an association between urbanisation and depression were in agreement with some studies from the USA (Blazer et al, 1987; Neff \& Husaini, 1987). A few studies from the Netherlands revealed higher urban than rural rates of psychosis (Marcelis et al, 1998; van Os et al, 2001, 2002). One of these studies

Table 2 Risks of psychosis and depression in women aged 25-64 years $(n=2189$ 190)

\begin{tabular}{|c|c|c|c|c|c|c|c|c|}
\hline \multirow[t]{3}{*}{ Variable } & \multicolumn{4}{|c|}{ Psychosis } & \multicolumn{4}{|c|}{ Depression } \\
\hline & \multicolumn{2}{|c|}{ Age-adjusted model } & \multicolumn{2}{|c|}{ Full model } & \multicolumn{2}{|c|}{ Age-adjusted model } & \multicolumn{2}{|c|}{ Full model } \\
\hline & $\begin{array}{c}\beta \text { estimate } \\
\text { (s.e.) }\end{array}$ & $\begin{array}{c}\text { Hazard ratio } \\
\qquad(95 \% \mathrm{Cl})\end{array}$ & $\begin{array}{c}\beta \text { estimate } \\
\text { (s.e.) }\end{array}$ & $\begin{array}{c}\text { Hazard ratio } \\
\qquad(95 \% \mathrm{Cl})\end{array}$ & $\begin{array}{c}\beta \text { estimate } \\
\text { (s.e.) }\end{array}$ & $\begin{array}{c}\text { Hazard ratio } \\
(95 \% \mathrm{Cl})\end{array}$ & $\begin{array}{c}\beta \text { estimate } \\
(95 \% \mathrm{Cl})\end{array}$ & $\begin{array}{c}\text { Hazard ratio } \\
\qquad(95 \% \mathrm{Cl})\end{array}$ \\
\hline \multicolumn{9}{|l|}{ Urbanisation } \\
\hline QI (low) & & I & & 1 & & 1 & & I \\
\hline Q2 & $0.12(0.069)$ & 1.12 (0.98-I.29) & $0.10(0.069)$ & $1.10(0.96-1.26)$ & $0.03(0.042)$ & $1.03(0.95-1.12)$ & $0.03(0.042)$ & $1.03(0.95-1.12)$ \\
\hline Q3 & $0.26(0.067)$ & $1.29(1.14-1.48)$ & $0.20(0.067)$ & 1.22 (I.07-1.39) & $0.07(0.042)$ & 1.07 (0.99-I.I7) & $0.06(0.042)$ & $1.06(0.97-1.15)$ \\
\hline Q4 & $0.60(0.063)$ & 1.83 (I.62-2.07) & $0.39(0.064)$ & 1.48 (I.3I-I.68) & $0.23(0.04 I)$ & 1.27 (I.I7-I.37) & $0.15(0.04 I)$ & $1.17(1.08-1.26)$ \\
\hline Q5 (high) & $0.98(0.060)$ & $2.66(2.36-2.99)$ & $0.57(0.062)$ & 1.77 (I.56-I.99) & $0.36(0.040)$ & $1.43(1.32-1.55)$ & $0.18(0.042)$ & $1.20(1.11-1.30)$ \\
\hline \multicolumn{9}{|l|}{ Marital status } \\
\hline Living alone & & & I.I7 (0.040) & $3.23(2.98-3.49)$ & & & $0.5 \mathrm{I}(0.027)$ & $1.66(1.58-1.75)$ \\
\hline Married/cohabiting & & & & I & & & & I \\
\hline \multicolumn{9}{|l|}{ Education } \\
\hline Low & & & $0.61(0.066)$ & $1.85(1.62-2.10)$ & & & $0.37(0.046)$ & $1.45(1.33-1.58)$ \\
\hline Middle & & & $0.17(0.062)$ & $1.19(1.05-1.34)$ & & & $0.12(0.042)$ & $1.12(1.04-1.22)$ \\
\hline High & & & & 1 & & & & 1 \\
\hline \multicolumn{9}{|l|}{ Immigrant status } \\
\hline Labour migrant & & & $0.4 I(0.058)$ & I.5I (I.35-I.69) & & & $0.20(0.044)$ & $1.22(1.12-1.33)$ \\
\hline Refugee & & & $0.57(0.06 \mathrm{I})$ & I.77 (I.57-I.99) & & & $0.24(0.050)$ & $I .28(I .16-I .4 I)$ \\
\hline Swedish-born & & & & I & & & & \\
\hline
\end{tabular}


Table 3 Risks of psychosis and depression in men aged 25-64 years $(n=224830$ I)

\begin{tabular}{|c|c|c|c|c|c|c|c|c|}
\hline \multirow[t]{3}{*}{ Variable } & \multicolumn{4}{|c|}{ Psychosis } & \multicolumn{4}{|c|}{ Depression } \\
\hline & \multicolumn{2}{|c|}{ Age-adjusted model } & \multicolumn{2}{|c|}{ Full model } & \multicolumn{2}{|c|}{ Age-adjusted model } & \multicolumn{2}{|c|}{ Full model } \\
\hline & $\begin{array}{c}\beta \text { estimate } \\
\text { (s.e.) }\end{array}$ & $\begin{array}{c}\text { Hazard ratio } \\
(95 \% \mathrm{Cl})\end{array}$ & $\begin{array}{c}\beta \text { estimate } \\
\text { (s.e.) }\end{array}$ & $\begin{array}{c}\text { Hazard ratio } \\
\qquad(95 \% \mathrm{Cl})\end{array}$ & $\begin{array}{c}\beta \text { estimate } \\
\text { (s.e.) }\end{array}$ & $\begin{array}{c}\text { Hazard ratio } \\
(95 \% \mathrm{Cl})\end{array}$ & $\begin{array}{c}\beta \text { estimate } \\
\text { (s.e.) }\end{array}$ & $\begin{array}{c}\text { Hazard ratio } \\
\qquad(95 \% \mathrm{Cl})\end{array}$ \\
\hline \multicolumn{9}{|l|}{ Urbanisation } \\
\hline QI (low) & & I & & I & & I & & I \\
\hline Q2 & $-0.04(0.069)$ & $0.96(0.84-1.09)$ & $0.07(0.069)$ & $\mathrm{I} .07$ (0.93-I.22) & $-0.03(0.047)$ & $0.97(0.89-1.07)$ & $0.02(0.047)$ & $1.02(0.93-1.12)$ \\
\hline Q3 & $0.16(0.066)$ & $1.17(1.03-1.33)$ & $0.27(0.066)$ & I.3I (I.I5-I.49) & $-0.02(0.047)$ & $0.98(0.89-1.07)$ & $0.03(0.047)$ & $1.03(0.94-1.13)$ \\
\hline Q4 & $0.49(0.061)$ & $1.63(1.45-1.84)$ & $0.42(0.062)$ & $1.53(1.36-1.73)$ & $0.05(0.046)$ & $1.06(0.97-I .16)$ & $0.04(0.047)$ & $1.04(0.95-1.14)$ \\
\hline Q5 (high) & $0.81(0.058)$ & $2.25(2.0 \mathrm{I}-2.52)$ & $0.52(0.059)$ & I.68 (I.50-I.89) & $0.24(0.045)$ & $1.27(1.17-1.39)$ & $0.12(0.047)$ & $1.12(1.03-1.23)$ \\
\hline \multicolumn{9}{|l|}{ Marital status } \\
\hline Living alone & & & $\mathrm{I} .79(0.050)$ & $6.02(5.45-6.64)$ & & & $0.66(0.032)$ & $1.93(1.81-2.05)$ \\
\hline Married/cohabiting & & & & 1 & & & I & 1 \\
\hline \multicolumn{9}{|l|}{ Education } \\
\hline Low & & & $0.92(0.076)$ & $2.52(2.17-2.93)$ & & & $0.27(0.052)$ & I.3I (I.I8-I.45) \\
\hline Middle & & & $0.4 I(0.074)$ & I.5I (I.3I-I.75) & & & $0.09(0.049)$ & $1.10(1.00-1.2 \mathrm{I})$ \\
\hline High & & & & I & & & & I \\
\hline \multicolumn{9}{|l|}{ Immigrant status } \\
\hline Labour migrant & & & $0.29(0.066)$ & I.34 (I.I7-I.52) & & & $0.04(0.057)$ & $1.04(0.93-1.16)$ \\
\hline Refugee & & & $0.72(0.060)$ & $2.06(1.83-2.32)$ & & & $0.26(0.059)$ & $1.30(1.15-1.46)$ \\
\hline Swedish-born & & & & I & & & & I \\
\hline
\end{tabular}

confirmed that a high level of urbanisation was associated with psychotic disorders, after adjustment for individual demographic and socio-economic characteristics, findings in agreement with our study (van Os et al, 2002). However, a study from the UK showed strong urban-rural differences in mental health that did not remain after adjustment for individual socioeconomic characteristics (Paykel et al, 2000). Other studies from the USA and the UK did not agree with our study, finding no urban-rural difference in mental health (Romans-Clarkson et al, 1990; Robins \& Regier, 1991; Kessler et al, 1994; Parikh et al, 1996). In Canada, no difference was found for depression rates in urban and rural Ontario (Parikh et al, 1996).

In summary, previous studies of possible urban-rural differences in mental health are inconsistent. However, our findings of a significant relationship between the level of urbanisation and psychiatric morbidity shed new light on this inconsistency, because our study population consisted of the entire adult population in Sweden, and we used incidence rates, rather than prevalence rates, as our outcome.

\section{Possible pathways}

The pathways linking urbanisation and mental health have not yet been clarified. For example, a British study based on data from 9777 individuals showed urban-rural differences in psychiatric morbidity and substance misuse, which were largely attributable to more adverse living circumstances among individuals in urban social environments. These adverse circumstances included stressful life events and low levels of social support (Paykel et al, 2000). Social networks have been shown to be better in rural areas than in urban areas for women (Romans-Clarkson et al, 1990). In addition, several previous studies have shown a relationship between mood disorders, suicide attempts and poor social networks (Amann, 1991; Johnsson Fridell et al, 1996; Cheng et al, 2000; Hirschfeld et al, 2000); thus, poor social networks might be a mediator between urbanisation and mental health. Another possible pathway linking urbanisation and psychiatric disease is that an urban environment might influence mental health in early life and increase general vulnerability to schizophrenia later in life (Marcelis et al, 1999; Pedersen \&
Mortensen, 2001). Some early risk factors associated with schizophrenia are prenatal exposure to viral infections (Takei et al, 1995) and poor nutrition (Brown et al, 1995). Other possible pathways between urbanisation and schizophrenia have also been discussed, such as daily life stress (van Os \& McGuffin, 2003) and chronic difficulties in urban areas (Brown $\&$ Prudo, 1981).

In The Netherlands it was found that about three-quarters of individuals living in urban areas had also been born there (Marcelis et al, 1999). These findings indicate a relatively stable urban-rural exposure over time, supporting the theory that being born and/or spending one's childhood in an urban environment increases the risk of later developing a psychotic disorder. Some urban areas might also be socio-economically deprived and ethnically segregated. However, these possible pathways between urbanisation and mental health were not included in our study. Finally, it is possible that there might be a biological synergism between genetic liability and urban exposure. In a study from The Netherlands, the authors found that both the level of urbanisation and familial 
liability (defined as a family history of delusions and/or hallucinations necessitating psychiatric treatment) increased the risk of psychotic disorder, independently of each other. Moreover, the effect of urbanisation on the additive scale was much larger for people with evidence of familial liability than for those without familial liability (van Os et al, 2003).

\section{Limitations and strengths}

There are some limitations to this study. First, the database of the whole Swedish adult population included only marital status as a measure of social support. If rural areas have better social support than urban ones, it is possible that people experiencing a first episode of psychosis or depression are less likely to be admitted to hospital in rural areas. This might lead to underestimates of the incidence of rural psychosis and depression owing to the effects of community rather than institutional care. It is also possible that the distribution of psychiatric beds across Sweden would bias our results if, for example, the number of psychiatric beds was higher in urban areas; however, we found that in the urbanised area of Stockholm County the number of psychiatric beds was 0.52 per 1000 inhabitants, and in the rural northern region it was 0.58 per 1000 inhabitants. The fact that cohabiting persons without children in common are registered as living alone may result in underestimates of the risks of psychiatric disease. Another limitation is that we were not able to adjust our results for possible effects of selective migration (e.g. from rural to urban areas), and the stress related to that migration. However, after adjustment of our results for migration between SAMS areas, the hazard ratios remained unaltered.

Our study also has a number of strengths. For example, the prospective nature of our data allowed us to calculate incidence rates of psychosis and depression, rather than prevalence rates. Data from the national database were nearly complete for all variables. This completeness is made possible by the Swedish registration system, which provides a personal identification number for each individual. This number is used to link data from different registers, and was used to follow each individual during the entire study period.

Our urbanisation measure, calculated as population density, is an actual measure of number of people per unit area. In

\section{CLINICAL IMPLICATIONS}

- For clinicians in urban areas, it is important to consider the level of urbanisation in the treatment and prevention of psychosis and depression.

- This is even more important in the treatment of patients who are living alone, have a low educational attainment and/or come from a foreign country.

Decision-makers should consider the level of urbanisation when planning the distribution of economic resources to psychiatric health care.

\section{LIMITATIONS}

- There was a lack of data on social support. Rural hospital admissions may not accurately reflect onset of psychiatric disorder if social support is better in rural than in urban areas.

- The fact that cohabiting people without children in common are registered as living alone might lead to underestimates of the risks of psychiatric disease.

- We were not able to adjust our results for possible effects of selective migration (e.g. from rural to urban areas) and the stress related to that migration.

KRISTINA SUNDQUIST, MD, PhD, GÖLIN FRANK, MSc, JAN SUNDQUIST, MD, PhD, Family Medicine, Karolinska Institutet, Stockholm, Sweden

Correspondence: Dr Kristina Sundquist, Family Medicine Stockholm, Karolinska Institutet, Alfred Nobels allé 12, SE-14I 83 Huddinge, Sweden. Tel: +468524887 08; fax: +468524887 06; e-mail: Kristina.Sundquist@klinvet.ki.se

(First received 8 May 2003, final revision 12 September 2003, accepted 29 October 2003)

another study of urbanisation the population density was calculated as number of addresses per unit area (van Os et al, 2002), which is not a precise measure of the actual number of people in that area. The level of urbanisation was estimated in one study according to the respondent's own judgement, which implies a self-report bias (Paykel et al, 2000).

Our study population consisted of all Swedish women and men aged $25-64$ years, in total 4.4 million persons. The validity of the diagnosis from the Swedish In-Care Register has been shown to be high in an evaluation by the Swedish National Board of Health and Social Welfare (National Board of Health and Welfare, 2000).

\section{Implications}

Our findings suggest that the level of urbanisation is associated with psychosis and depression in both women and men. For clinicians in urban areas who are involved in both treatment and prevention of disease, it is of great importance to consider possible pathways in the development of psychiatric morbidity. These pathways might include lack of social support, stressful life events and familial liability. Moreover, when planning the distribution of health care resources, it is important to consider the level of urbanisation in order to improve services for people who are at high risk of developing psychiatric morbidity.

\section{ACKNOWLEDGEMENTS}

This work was supported by grants from the National Institutes of Health (I ROI HL7I084-0I), the Swedish Council for Working Life and Social Research (200I-2373), the Swedish Research Council (K200I-27X-II65I-06C), the Knut and Alice Wallenberg Foundation, and Stockholm County Council. The authors thank Sanna Sundquist, student at Foothill College, California, for technical assistance. 


\section{REFERENCES}

Amann, G. (1991) Social network and social suppor deficits in depressed patients: a result of distorted perception? European Archives of Psychiatry and Clinical Neuroscience, 24I, 49-56.

American Psychiatric Association (1994) Diagnostic and Statistical Manual of Mental Disorders (4th edn) (DSM-IV). Washington, DC: APA.

Blazer, D., Crowell, B. A. \& George, L. K. (1987) Alcohol abuse and dependence in the rural South. Archives of General Psychiatry, 44, 736-740.

Breslow, N. E. \& Day, N. E. (1987) Statistical Methods in Cancer Research. Vol. 2: The Design and Analysis of Cohort Studies. Lyon: International Agency for Research on Cancer.

Brown, G.W. \& Prudo, R. (198I) Psychiatric disorder in a rural and an urban population: I. Aetiology of depression. Psychological Medicine, II, 58I-599.

\section{Brown, A. S., Susser, E. S., Lin, S. P., et al (1995)} Increased risk of affective disorders in males after second trimester prenatal exposure to the Dutch hunger winter of 1944-45. British Journal of Psychiatry, 166, 601-606.

Carroll, L. J., Cassidy, J. D. \& Cote, P. (2003) Factors associated with the onset of an episode of depressive symptoms in the general population. Journal of Clinical Epidemiology, 56, 65I-658.

\section{Cheng, A. T., Chen, T. H., Chen, C. C., et al (2000)} Psychosocial and psychiatric risk factors for suicide: case-control psychological autopsy study. British Journal of Psychiatry, 177, 360-365.

Hirschfeld, R. M., Montgomery, S. A., Keller, M. B., et al (2000) Social functioning in depression: a review. Journal of Clinical Psychiatry, 61, 268-275.

Johnsson Fridell, E., Ojehagen, A. \& TraskmanBendz, L. (1996) A 5-year follow-up study of suicide attempts. Acta Psychiatrica Scandinavica, 93, I5I-157.

Kessler, R. C., McGonagle, K. A., Zhao, S., et al (1994) Lifetime and I2-month prevalence of DSM-III-R psychiatric disorders in the United States. Results from the National Comorbidity Survey. Archives of General Psychiatry, 5I, 8-19.

Kleinbaum, D. G. (1995) Survival Analysis. New York: Springer.

Marcelis, M., Navarro-Mateu, F., Murray, R., et al (1998) Urbanization and psychosis: a study of 1942-1978 birth cohorts in The Netherlands. Psychological Medicine 28, 87I-879.

Marcelis, M., Takei, N. van Os, J. (1999) Urbanization and risk for schizophrenia: does the effect operate before or around the time of illness onset? Psychological Medicine, 29, 1197-1203.

National Board of Health and Welfare (2000) Värdering av diagnoskvaliteten för akut hjärtinfarkt i patientregistret 1987 och 1995 [Validity of Quality of Diagnosis for Acute Myocardial Infarction in the Patient Registers for 1987 and 1995]. Not available in English. Stockholm: Epidemiologiskt Centrum, Socialstyrelsen. http: / / www.sos.se/epc/pdf/rapp8795.pdf

Neff, J. A. \& Husaini, B. A. (1987) Urbanicity, race and psychological distress. Journal of Community Psychology, 15, 520-536.

Parikh, S. V., Wasylenki, D., Goering, P., et al (1996) Mood disorders: rural/urban differences in prevalence, health care utilization, and disability in Ontario. Journal of Affective Disorders, 38, 57-65.

Paykel, E. S., Abbott, R., Jenkins, R., et al (2000) Urban-rural mental health differences in Great Britain: findings from the national morbidity survey. Psychological Medicine, 30, 269-280.

Pedersen, C. B. \& Mortensen, P. B. (200I) Evidence of a dose-response relationship between urbanicity during upbringing and schizophrenia risk. Archives of General Psychiatry, 58, 1039-1046.

Robins, L. N. \& Regier, D. A. (eds) (199I) Psychiatric Disorders in America: The Epidemiologic Catchment Area Study. New York: Free Press.

Romans-Clarkson, S. E., Walton, V. A., Herbison, G. P., et al (1990) Psychiatric morbidity among women in urban and rural New Zealand: psycho-social correlates. British Journal of Psychiatry, 156, 84-91.

SAS (1989) SAS/STAT User's Guide, Version 6 (4th edn), vol. I. Cary, NC: SAS Institute.

Sundquist, J. \& Johansson, S.-E. (eds) (2002) Födelselandets betydelse: hälsan i olika invandrar grupper Sverige [The Importance of The Country of Birth: Health in Different Immigrant Groups in Sweden]. Stockholm: Folkhälsoinstitutet.

Takei, N., Sham, P. C., O'Callaghan, E., et al (1995) Schizophrenia: increased risk associated with winter and city birth - a case-control study in 12 regions within England and Wales. Journal of Epidemiology and Community Health, 49, 106-107.

van Os, J. \& McGuffin, P. (2003) Can the social environment cause schizophrenia? British Journal of Psychiatry, 182, 291-292.

van Os, J., Hanssen, M., Bijl, R.V., et al (200I) Prevalence of psychotic disorder and community level of psychotic symptoms: an urban-rural comparison. Archives of General Psychiatry, 58, 663-668.

van Os, J., Hanssen, M., de Graaf, R., et al (2002) Does the urban environment independently increase the risk for both negative and positive features of psychosis? Social Psychiatry and Psychiatric Epidemiology, 37, 460-464.

van Os, J., Hanssen, M., Bak, M., et al (2003) Do urbanicity and familial liability coparticipate in causing psychosis? American Journal of Psychiatry, 160, 477-482.

Westman, J., Hasselstrom, J., Johansson, S. E., et al (2003) The influences of place of birth and socioeconomic factors on attempted suicide in a defined population of 4.5 million people. Archives of General Psychiatry, 60, 400-414.

World Health Organization (1978) International Statistical Classification of Diseases and Related Health Problems (ICD-9). Geneva: WHO.

World Health Organization (1992) International Statistical Classification of Diseases and Related Health Problems (ICD-10). Geneva: WHO. 